\title{
MANUEL ITUARTE Y EL DIBUJO DE ARQUITECTURA
}

LOUiSE NoElLE

El dibujo de arquitectura es un difícil arte que trata de conciliar exactitud con creatividad, un instrumento a la vez analítico y expresivo. Por una parte, es evidente que el arquitecto se ha servido del dibujo, a lo largo de los siglos, como un elemento para transmitir sus conceptos arquitectónicos y poder así llevarlos a cabo; es el caso de los diversos diseños, plantas, cortes y perspectivas, entre otros, que conforman el principal medio de comunicación entre arquitectos, clientes y operarios. En estos ejemplos se trata de representaciones previas a la construcción, donde queda patente la creatividad del arquitecto que es capaz de concebir el edificio con sus diversos espacios y formas, para llevarlo posteriormente a cabo.

Por otra parte, los arquitectos, tanto dentro de su aprendizaje como en su práctica profesional, han recurrido al dibujo como medio de conocimiento de la historia de la arquitectura. Esta actividad fue parte integral de los planes de estudio, sobre todo en las academias de bellas artes, aunque actualmente ha sido abolida en la mayoría de las escuelas. Se trataba tanto de la copia de los diversos manuales y catálogos de construcciones, como del dibujo directo de monumentos importantes. La exactitud y veracidad que este tipo de trabajo requieren no obsta para que la expresión personal se haga presente, imbuyendo a la obra de un carácter artístico. En efecto, basta recordar los envíos hechos a Beaux arts de París por los ganadores del Prix de Rome, ${ }^{1}$ o los dibujos efectuados por Federico Mariscal ante el legado prehispánico, reproducidos en Estudios arquitectónicos de las minas mayas. Yucatán y Campeche; ${ }^{2}$ en todos estos casos está patente tanto el estilo personal del dibujante, como su emoción ante el monumento y su deseo de ofrecer con el mejor ángulo el aspecto más atractivo.

En el caso que nos ocupa, se puede afirmar que Manuel Ituarte incursionó

${ }^{1}$ El catálogo Paris-Rome-Athens. Travels in Greece by French Architects in the Nineteenth and Twentieth Centuries, de la exposición en el Museo de Bellas Artes de Houston, julio 1983, muestra claramente esta creatividad

${ }^{2}$ Federico E Mariscal, Estudio arquitectónico de las minas maýas. Yucatány Campeche, México, Secretaría de Educación Pública, 1928. 
en los dos tipos de dibujo y con indudable éxito, como lo veremos a continuación. Por una par te aún existen, aunque escasos, elementos gráficos de sus proyectos arquitectónicos. Por la otra, en cantidad numerosa han llegado hasta nuestros días diversos dibujos realizados por él frente a los monumentos arquitectónicos. Así este estudio ha sido inspirado por una libreta de apuntes que lo acompañó en un viaje al viejo continente en 1910 , donde quedaron recogidos edificios y detalles de París y sus alrededores." Estas obras, aunadas a la excelente opinión que de él tuvieron amigos y discípulos, motivan el tratar de subsanar la falta de noticias existentes sobre este arquitecto.

Manuel María Ituarte Esteva nace en la ciudad de México el 29 de julio de 1877 y muere el 5 de octubre de 1937. Ingresa a la Escuela de Bellas Artes para cursar los estudios de arquitectura. Entre otros, fue discípulo de Antonio Rivas Mercado, así como de los arquitectos europeos con que contaba la escuela por entonces, como Adamo Boari y Paul Dubois. De entre sus compañeros de clase destacan Federico E. Mariscal (1881-1971) y Jesús T. Acevedo (1882-1918)." Con el tema "Museo de Historia Natural y Arqueología", realiza su examen profesional el 4 de octubre de 1907, siendo aprobado por unanimidad por los siguientes sinodales: Antonio Rivas Mercado, director de la escuela; José Rivero, Mariano Lozano, Adamo Boari y Carlos Herrera ${ }^{5}$ Asimismo, estos profesores pidieron por escrito que se le otorgase la pensión en Europa, "eximiéndolo del concurso respectivo en vista del brillante examen que sustentó". 6

Es indispensable apuntar aquí que con Manuel ingresó a la Escuela de

${ }^{3}$ Agradezco al arquitecto José $\mathrm{G}$. Beltrán Rueda el haberme mostrado estos dibujos, en la actualidad enmarcados individualmente, y el haberme facilitado, para su fotografía, los que ilustran este artículo. Sin su amable y generosa ayuda este trabajo no se hubiese realizado. Asimismo agradezco a la Lic Cecilia Gutiérrez y al Archivo Fotográfico del Instituto de Investigaciones Estéticas su colaboración en las reproducciones fotográficas.

${ }^{4}$ Para la información general sobre Manuel y Carlos Ituarte Esteva se consultaron diversas fuentes; para las fechas cabe señalar el Diccionario Porria Historia, biografía y geografía de México, 5a. ed., México, Porrúa, 1986 y Arquitectura del siglo XIX en México, México, Universidad Nacional Autónoma de México, 1973, de Israel Katzman Asimismo el ax quitecto Carlos Ituarte González me proporcionó amablemente informes y documentos en una entrevista efectuada el 4 de febrero de 1992.

${ }^{5}$ Información proporcionada por Xavier García Lascuráin, quien ha elaborado un listado con los datos de los ax quitectos recibidos en la Escuela de Arquitectura de la ciudad de México entre 1860 y 1939 , detallando el tema de la tesis y los sinodales

${ }^{6}$ Cfr. Legajo sobre Manuel Ituarte, Archivo de la Escuela Nacional de Arquitectura, actualmente en la Facultad de Arquitectura, Universidad Nacional Autónoma de México. En esta documentación se encuentra también pormenorizada su labor docente, a la que se hace referencia más adelante. Quiero agradecer aqui al maestro Eduardo Báez su asesoría en la consulta de estos archivos que él ha venido estudiando sistemáticamente 
Arquitectura su hermano Carlos Alberto, nacido el 30 de marzo de 1879 y fallecido el 29 de junio de 1929 en la ciudad de México. Obtuvo su título profesional en la misma época, el 31 de octubre de 1907, con el tema "Un observatorio astronómico"; en este caso fungieron como jurados Antonio Rivas Mercado, Antonio Torres Torija, José Rivero, Adamo Boari y Carlos Lazo, quienes también solicitaron que se le concedierala pensión de Europa. ${ }^{7}$

Ambos arquitectos Ituarte ingresaron como maestros a la Escuela de Arquitectura en 1908, dictando a través de los años diversas cátedras. Se debe señalar que Carlos se inclinaba por las materias técnicas mientras que Manuel sobresalía en las artísticas, complementándose así en su trabajo profesional. Efectivamente, Carlos fue profesor de Estereotomía y de Carpintería y Estructuras de hierro entre 1908 y 1911, de Geometría descriptiva de 1909 a 1911, de Trazo de sombras, perspectiva y estereotomía, de 1911 a 1914, de Arquitectura comparada y de Composición de elementos de los edificios de 1914 a 1916, y de Construcción y de Levantamiento de planos y nivelaciones de 1917 a 1921. Además, en 1916 fue electo por sus colegas como representante técnico de arquitectura y fungió en 1915 como profesor de Teoría de la arquitectura y de Estereotomía en la Escuela Nacional de Ingeniería. Finalmente cabe mencionar que fue Oficial dibujante de la Secretaría de Instrucción Pública y Arquitecto valuador de la Comisión Pericial del Distrito Federal. ${ }^{8}$

Por su parte, Manuel se inició como profesor de Estilos de ornamentación en los edificios en 1908, reemplazando a Samuel Chávez; en 1910 dicta un curso de Materiales y artículos de la construcción ý para 1911 es nombrado profesor de Acuarela; en 1912 retomala cátedra de Estilos de ornamentación que dejaba Jesús T. Acevedo, y en 1914 reemplaza a Maxime Roisin en Composición. Para 1916 reemplaza a Ignacio de la Hidalga en Arquitectura comparada, y en 1919 a Antonio Rivas Mercado en el segundo y tercer cursos de Composición. Es claro que este arquitecto tuvo una larga trayectoria deñtro de la docencia, siendo recordado en especial por sus clases de acuarela. Es por ello que, a pesar de su fama de faltista en la escuela, se le reconoce como el maestro de connotados acuarelistas ${ }^{9}$ Dentro de este mismo rubro,

\footnotetext{
${ }^{7}$ La pensión no fue otorgada ni a Carlos ni a Manuel, aduciendo que debían presentarse a concurso.

${ }^{8}$ Cfr. Legajo sobre Carlos Ituarte, archivo de la Escuela Nacional de Arquitectura, actualmente en la Facultad de Arquitectura de la UNAM. Gomo datos complementarios ofrecidos por Carlos Ituarte Gronzález el 4 de febrero de 1992, se puede agregar que estuvo casado con Angelina González Berazueta, con quien tuvo ocho hijos.

${ }_{9}^{9}$ El libro Arquitectos mexicanos y la acuarela, de Augusto Pérez Palacios, México, Editora Tlacaeceltzin, 1968, está dedicado a Manuel Ituarte como el maestro de los arquitectos
} 
Justino Fernández lo señala como uno de sus maestros en la dedicatoria de uno de sus primeros libros. ${ }^{10}$

También, diversos estudiantes de arquitectura lo recuerdan como uno de "los principales profesores que tenían influencia en la escuela"; es el caso de Enrique del Moral ${ }^{11}$ y de José Gorbea Trueba. ${ }^{12}$ Quien enfatiza también la importancia de este profesionista es Carlos Obregón Santacilia, ${ }^{13}$ al señalarlo como un arquitecto progresista que sintió "la necesidad de simplificar y por lo tanto de modernizar", y donde "alentaba un espíritu de renovación" dentro de la planta docente de la Escuela de Arquitectura. Asimismo agrega que "Manuelón" era una figura romántica tanto física como moralmente, de gran aliento en sus proyectos, así como "pintor estupendo, acuarelista y dibujante extraordinario, músico”, dedicándose a las artes en general Estos mismos conceptos son retomados posteriormente por Israel Katzman, ${ }^{14}$ quien lo señala como uno de los iniciadores del "tradicionalismo" en México junto con Federico Mariscal, al imbuir en sus alumnos el interés y estudio de los monumentos coloniales. Algunos arquitectos-artistas como Augusto Pérez Palacios, Alfredo Guati y Guillermo Zárraga también lo consideran como un importante preceptor. ${ }^{15}$

Por lo que se refiere a la práctica profesional arquitectónica, Manuel y Carlos establecieron su taller en el número 2 de la antigua calle de Cordobanes (hoy Donceles 87, esquina con Brasil), manteniendo una sociedad en todas las obras y proyectos realizados. Poco es lo que se ha registrado de este quehacer y menos aún lo que se conserva, casi siempre en un grado avanzado de deterioro. Es el caso de buen número de casas y edificios departamentales, como la casa de estilo neoclásico de Luis Moya 53 o el edificio de Puente de Alvarado 64, de inspiración colonial; otras casas neocoloniales de esa época han sido destruidas y tan sólo se ha conservado un excelente ejemplo de arquitectura beauxarts en Tabasco 197, obra de 1921, que destaca por la calidad de su factura

acuarelistas; Manuel Guati realizó un texto de presentación, incluyendo once trabajos de Ituarte; además, una acuarela suya ilustra la portada.

${ }^{10}$ Justino Fernández, El arte moderno en México, breve historia Siglos XIX y XX, México, Robredo-Porrúa, 1937

${ }^{11}$ Cfr. Salvador Pinoncelly, La obra de Enrique del Moral, México, Universidad Nacional Autónoma de México, 1983, p. 5

${ }^{12}$ Cfr. "Testimonios vivos, 20 arquitectos", Cuadernos de arquitectura y conservación del patrimonio artístico, núms. 15-16, México, Instituto Nacional de Bellas Artes, 1981, p. 47.

${ }^{13} \mathrm{Cfr}$. Carlos Obregón Santacilia, Cincuenta años de arquitectura mexicana, México, Editorial Patria, 1952, p. 38.

${ }^{14} \mathrm{C} f r$. Israel Katzman, La arquitectura contemporánea mexicana, México, Instituto Nacional de Antropología e Historia, Secretaría de Educación Pública, 1963, pp. 80 y 112.

${ }^{15}$ Cfr. Nota 9. "Libro homenaje al gran artista, maestro y amigo, Manuel Ituarte", texto del prólogo, sin página. 
y la proporción del diseño. Asimismo, hay datos de dos escuelas, una en Querétaro, La Corregidora, y otra en la colonia Santa María. Finalmente es importante desatacar su intervención dentro del arreglo del edificio de la antigua Academia de San Carlos, que por entonces compartían la Escuela de Arquitectura y la de Artes Plásticas bajo la dirección de Antonio Rivas Mercado. Así, en julio de 1912 inician las obras relativas a la colocación de la cúpula del patio principal ${ }^{16}$ y el cambio de los barandales del piso superior por balaustres, con lo que se pudieron colocar en este espacio algunos de los yesos recién traídos por Carlos Lazo.

Dentro de otro rubro, el de la restauración, se pueden señalar diversas acciones, teniendo en cuenta que Manuel Ituarte fue además fundador y colaborador de la Dirección de Monumentos Coloniales. Así, tiene en su haber la restauración de los conventos de San Agustín de Acolman, de San Andrés Calpan y de Churubusco, y muy especialmente del patio del exconvento de La Merced. Asimismo, estos arquitectos realizaron la conservación del Palacio Municipal de Veracruz. Aquí es importante señalar la relación amistosa entre los arquitectos Ituarte y sus condiscípulos Federico Mariscal y Jesús T. Acevedo, recordando tanto sus tendencias progresistas como su interés compartido por la revaloración y el rescate de la arquitectura colonial. Es una postura de la que dan fe tanto diversos escritos de Mariscal, como las conferencias de Acevedo en el Ateneo de la Juventud, ${ }^{17}$ y que se hace patente en los hermanos Ituarte tanto en su labor de restauración como en la reiteración en sus obras del estilo neocolonial.

En contraste, son numerosos los proyectos de gran envergadura que no llegaron a realizarse. Es el caso de un Museo de Bellas Artes en la Avenida Juárez y del monumento a Benito Juárez para erigirse en la Alameda, habiendo ganado el segundo premio en el concurso de $1909 .{ }^{18}$ Destaca, por su importancia, el proyecto del arreglo de la Plaza de la Constitución, con el que ganaron el concurso de 1917. Se trata de un planteo de inspiración académica donde se presenta como una plaza arbolada para el paseo dominical con diversos elementos de mobiliario urbano acordes en estilo; este arreglo ya incluía la apertura de la Avenida 20 de Noviembre y el

${ }^{16}$ Cfr . Legajo de correspondencia de 1912, archivo de la Escuela Nacional de Arquitectura, actualmente en la Facultad de Arquitectura de la Universidad Nacional Autónoma de México.

${ }^{17}$ Entre otros se pueden mencionar, de Federico Mariscal, La patria y la arquitectura nacional, México, Universidad Popular, 1915, y diversos artículos de El arte y la ciencia "En cuanto a Jesús T. Acevedo, algunas de sus conferencias están recogidas en Disertaciones de un arquitecto, México, Instituto Nacional de Bellas Artes, 1967.

${ }^{18}$ Información procedente de los libros de Justino Fernández, op cit, y de Israel Katzman, op cit. (Arquitectura del siglo XIX en México) 
quiosco, fuentes, balaustradas y bancas se disponían siguiendo un amable trazo curvilíneo. ${ }^{19}$

Para concluir, cabe mencionar otros dos proyectos, diseñados tan sólo por Manuel Ituarte después de la muerte de su hermano: la Estación terminal del ferrocarril de Buenavista y un Museo de Arte Religioso anexo a la Catedral sobre la calle de Seminario "Asimismo se tiene noticia de que en 1930 participó en el Primer Congreso Nacional de Planificación de la Secretaría de Comunicaciones y Obras Públicas con un trabajo sobre ciudades coloniales.

En este sentido es mayor la obra plástica que se conserva de Manuel Ituarte, y, a decir de sus discípulos, su trascendencia en este campo es también superior. En especial se le conoce como un excelente acuarelista, por lo que el Museo de la Acuarela, en la ciudad de México tiene en exhibición catorce de sus obras. ${ }^{20}$ Se trata de paisajes, detalles arquitectónicos y retratos, destacando "Museo de Historia Natural", 1907, ilustración de su tesis profesional; en ella se aprecia lo que sería el interior del edificio, estando realizada con gran detalle y muy bien trabajada, toda una lección de dibujo arquitectónico y del arte de la acuarela.

Dentro de esta disciplina también se pueden mencionar aquellas acuarelas que ilustran el libro editado por sus discípulos, ${ }^{21}$ en especial la que se muestra en la portada, una cúpula poblana. Por otra parte, se conocen numerosos ejemplos, como aquellos que se reseñan para la xxv Exposición de la Escuela de Bellas Artes, ${ }^{22}$ en esta ocasión los temas escogidos son diversos paisajes que van desde el "Ajusco" hasta "Versailles" pasando por la "Villa Borghese" y "Chapultepec". En casi todos estos casos, la arquitectura es el personaje siempre presente, como tema central de sus obras.

Dentro de esta actividad plástica también realizó diversos dibujos, de los que se tiene noticia desde 1891 en que participa en la Exposición número 22 de la Academia de San Carlos como alumno de la clase nocturna de Dibujo tomado de la estampa. ${ }^{23}$ También en la primera edición del Arte colonial en México de Manuel Toussaint se encuentra un dibujo de Ituarte de las

${ }^{19}$ Cfr. Entorno, núm. 3, México, octubre 1982, p. 10

${ }^{20}$ Museo de la Acuarela, Catálogo, Comité Organizador de los Juegos de la XIX Olimpiada, México, 1968. En esta publicación se ilustran "Dama con perro", 1911, y "Atardecer en Guanajuato", 1921.

${ }^{21}$ Cfr. nota 9 .

${ }^{22}$ XXV Exposición de la Escuela de Bellas Artes, 25 de diciembre de 1919 al 25 de enero de 1920. En el Cátálogo de esta Muestra se anotan 19 obras con los números de Catálogo 28 al 46 .

${ }^{23}$ Catálogo de la XXII Exposición de la Escuela Nacional de Bellas Artes, México, Imprenta de Ireneo Paz, 1891, p 46 
decoraciones de la iglesia de la Anunciación de Tlaxcala. ${ }^{24}$ Es dentro de esta línea de trabajo donde cobran relevancia los dibujos de arquitectura que aquí se presentan.

Efectivamente, en 1910 el joven arquitecto solicita tres meses de licencia de sus clases en la Escuela Nacional de Arquitectura, ${ }^{25}$ para poder cumplir con una comisión de la Compañía Bancaria de Obras y Bienes Raíces. Durante este viaje lleva una libreta de apuntes, a la manera de los arquitectos viajeros de esa época, donde quedan inscritas sus diversas impresiones del periplo. Su estancia, por lo que se ve en los dibujos, estuvo circunscrita a París y sus alrededores, amén de algún viaje corto hacia tierras italianas. El resultado de esta práctica académica quedó reflejado en una cincuentena de dibujos de su libreta, en la actualidad enmarcados independientemente; de ellos se reproducen doce en este artículo.

El carácter informal y casual de los dibujos es aparente, tanto en la variedad de temas tratados como en el diverso grado de trabajo y terminación que cada uno presenta. Sin embargo, es de señalar su calidad puesto que, de simples bocetos y recuerdos de viaje, pueden pasar fácilmente a ser exhibidos como obras autónomas de gran interés. Dentro de estos dibujos se pueden encontrar tres tipos de expresiones, retratos, apuntes de detalles arquitectónicos y edificios o interiores de los mismos. En este caso se reproduce el retrato de Cora Laparcerie, una artista de la época que interpretaba al personaje clásico Xantho; la dama fue probablemente captada dentro de una de sus representaciones. En cuanto a detalles arquitectónicos, encontramos una cabeza de león de Notre Dame dialogando con una puerta y una columna del Museo de Cluny, o el estudio de un candelabro del Panteón. De un carácter especial y tal vez más emotivo, son los croquis tomados en la casa de Víctor Hugo, posteriormente entintados e iluminados.

Más numerosos son los dibujos de arquitectura propiamente dichos y que responden a la preparación escolar y profesional de Manuel Ituarte. Asiñismo, se puede decir que es en este tipo de actividad donde se distingue especialmente logrando ejemplos de calidad e interés, sin olvidar que tal vez sean éstos los dibujos más trabajados. Dentro de los que aquí se incluyen, la fachada del Louvre, obra de Claude Perrault, es una muestra singular de este arte; el edificio se encuentra perfectamente centrado y enmarcado dentro de la pequeño hoja, ${ }^{26}$ y aunque se nota el trazo libre, éste es cuidadoso y

\footnotetext{
${ }^{24}$ Manuel Toussaint, Arte colonial en México, México, Universidad Nacional Autónoma de México, 1948, p. 57 , figs. 55 y 56 .

${ }^{25}$ Cfr nota 6

${ }^{26}$ Todos los dibujos están en las hojas de una libreta de $24 \times 16$ centímetros.
} 
minucioso. Con menos detalles están realizados la fachada de la Facultad de Derecho, en París, el remate lateral de Chantilly y una de las pilastras superiores del puente de Alejandro II sobre el Sena. Por otra parte, tanto en la vista de Montmartre como en el interior de Notre Dame, ceden la minuciosidad ante la emoción del sitio y la necesidad de transmitirla, acercándose a los paisajes impresionistas; tal vez en algunas obras que no se reproducen aquí sea más clara esta tendencia, donde se abandona la tinta y el lápiz duro para ofrecer, con algunos trazos menos definidos, la Avenida de Luxemburgo o el Jardín de las Tullerías; también es el caso de una espléndida vista del Louvre en el crepúsculo, donde se vale de los lápices de colores para enfatizar el dramatismo de la penumbra hendida por la luz eléctrica. Finalmente cabe señalar que en algunos dibujos de interiores, como la Sala Napoleón o la Galería de Apolo, destaca el estudio de los elementos decorativos. Más tarde, en relación con su cátedra de Estilos de ornamentación, estos elementos cobrarán especial importancia como parte de la enseñanza académica de esta época.

De este modo, una serie de dibujos realizados en 1910 por Manuel Ituarte nos ha permitido acercarnos al quehacer de un arquitecto de principios de siglo. Ha quedado establecida la importancia de este profesionista, tanto dentro de su labor como restaurador, como en su papel de maestro y de artista. En especial estos dibujos nos muestran su habilidad técnica aparejada con sus conocimientos de arquitectura, pero que no dejan de lado su talento creativo y su sensibilidad. Por ello, esta colección, que ha podido mantenerse intacta, representa un valioso legado de lo que fueron las enseñanzas de la antigua Academia de San Carlos y del talento de sus integrantes. Es de desear que no se disgregue y que en el futuro pase a formar parte de algún organismo oficial donde esté al alcance de los interesados en la materia. Conocer los valores de la arquitectura académica nos ayudará a apreciarla y conservarla; el interés y la calidad de los dibujos de Mănuel Ituarte coadyuvan en esta instancia ofreciendo además una agradable visión de la Europa de 1910. 
DOI: http://dx.doi.org/10.22201/iie.18703062e.1993.64.1667

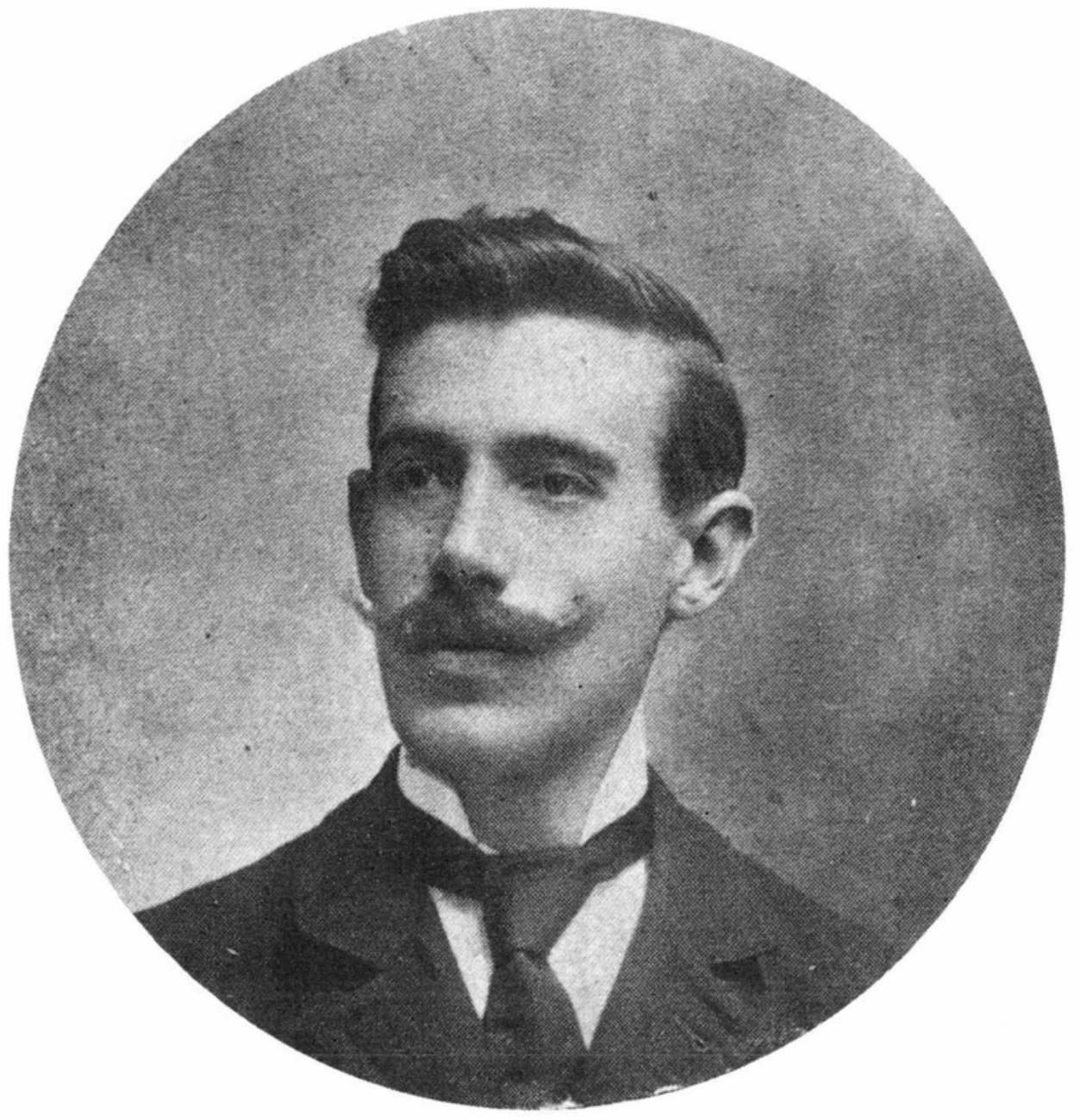

1. Manuel Ituarte. 
DOI: http://dx.doi.org/10.22201/iie.18703062e.1993.64.1667

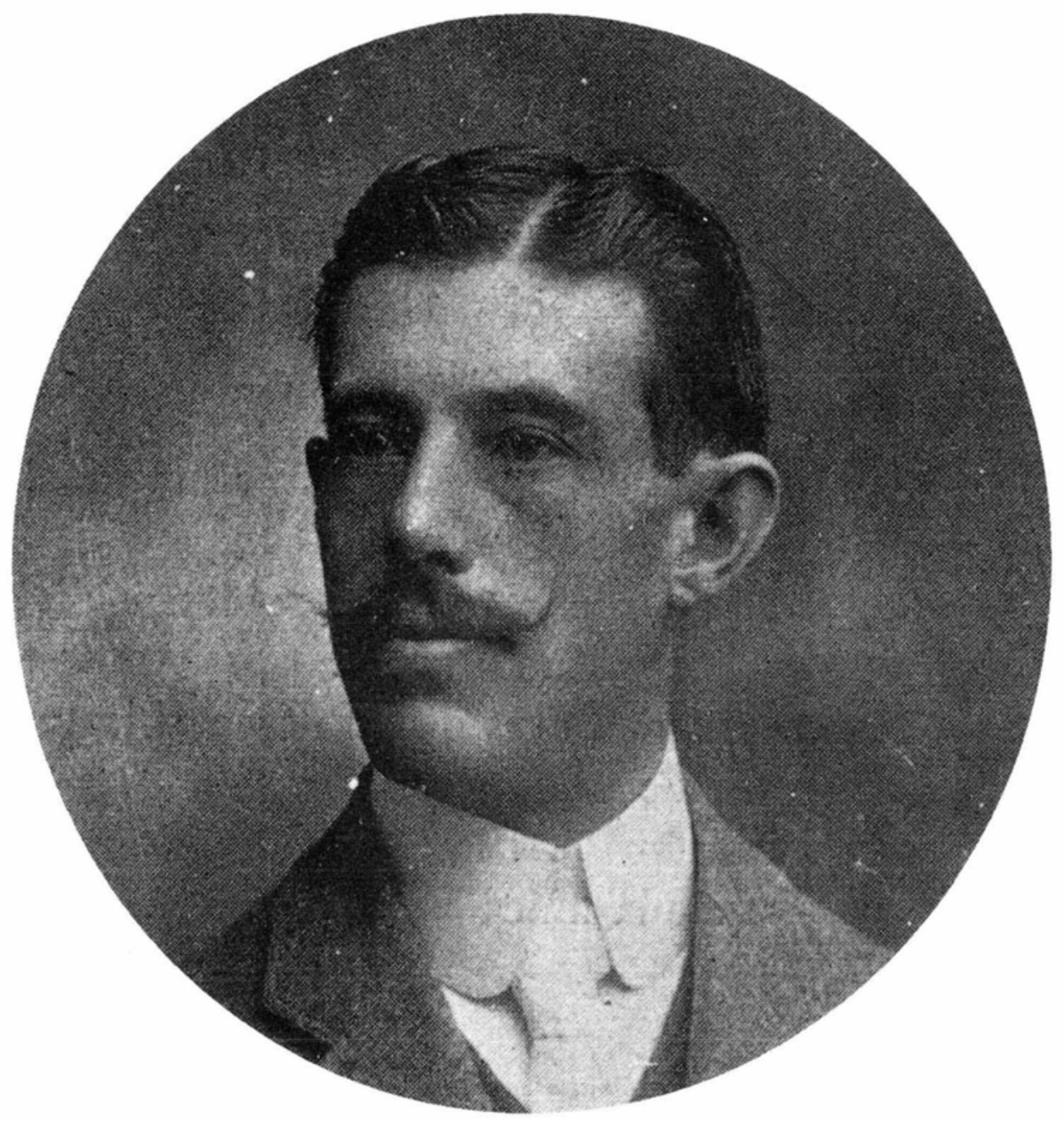

2. Carlos Ituarte. 


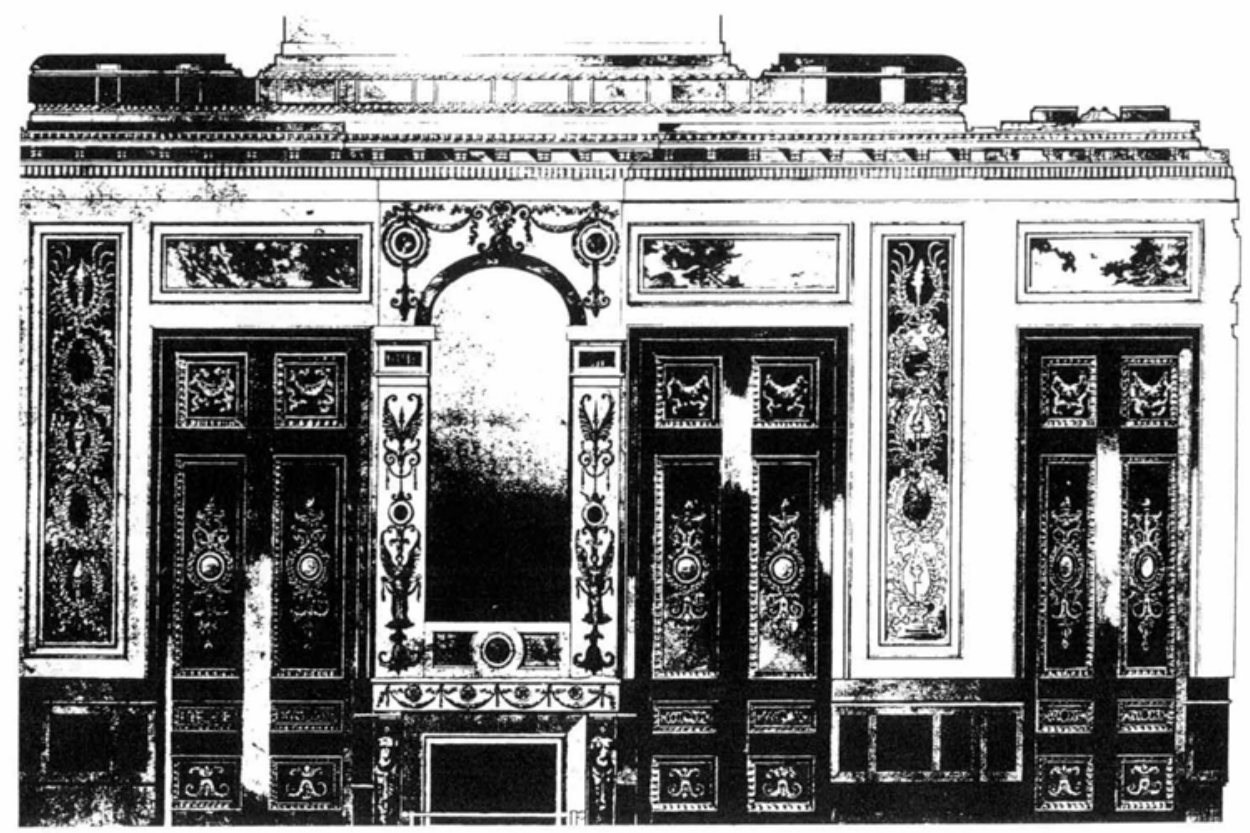

3. Proyecto para un salón de recepción. Dibujo acuarelado. 


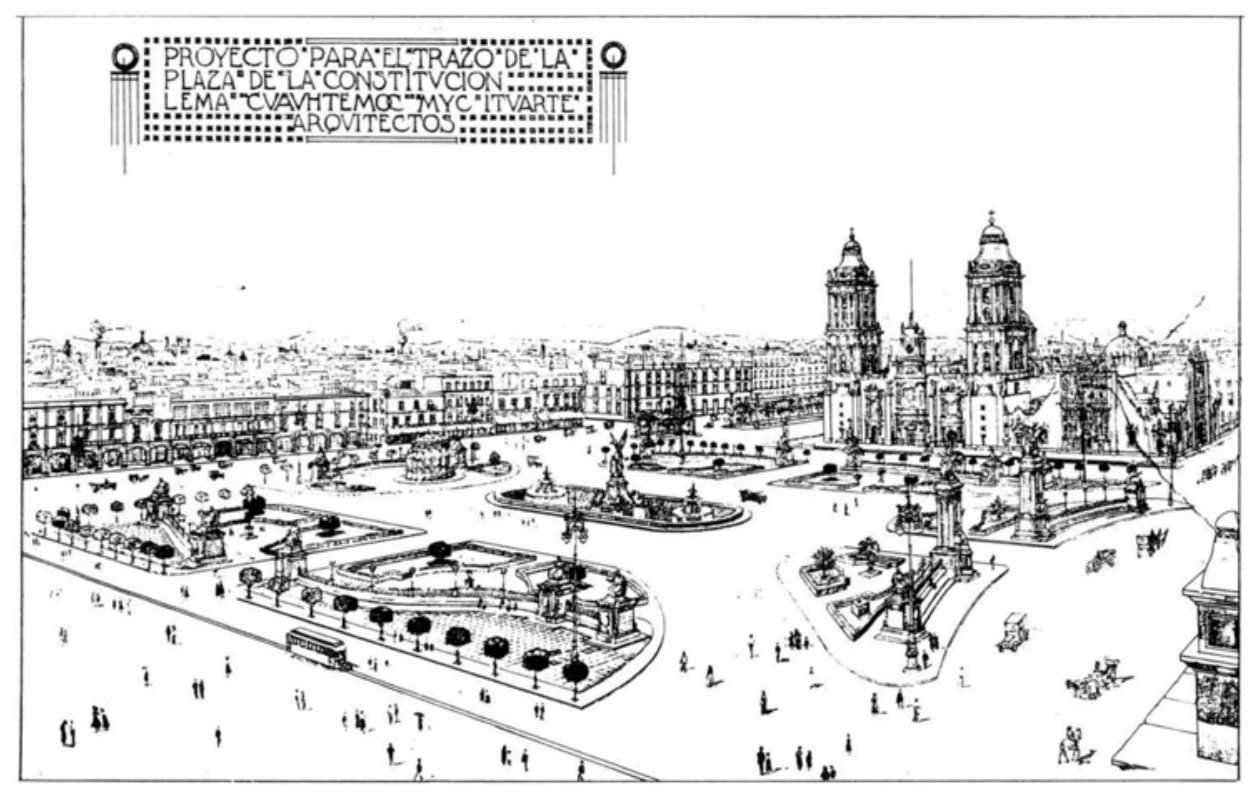

4. Proyecto para la Plaza de la Constitución, 1915. Dibujo. 


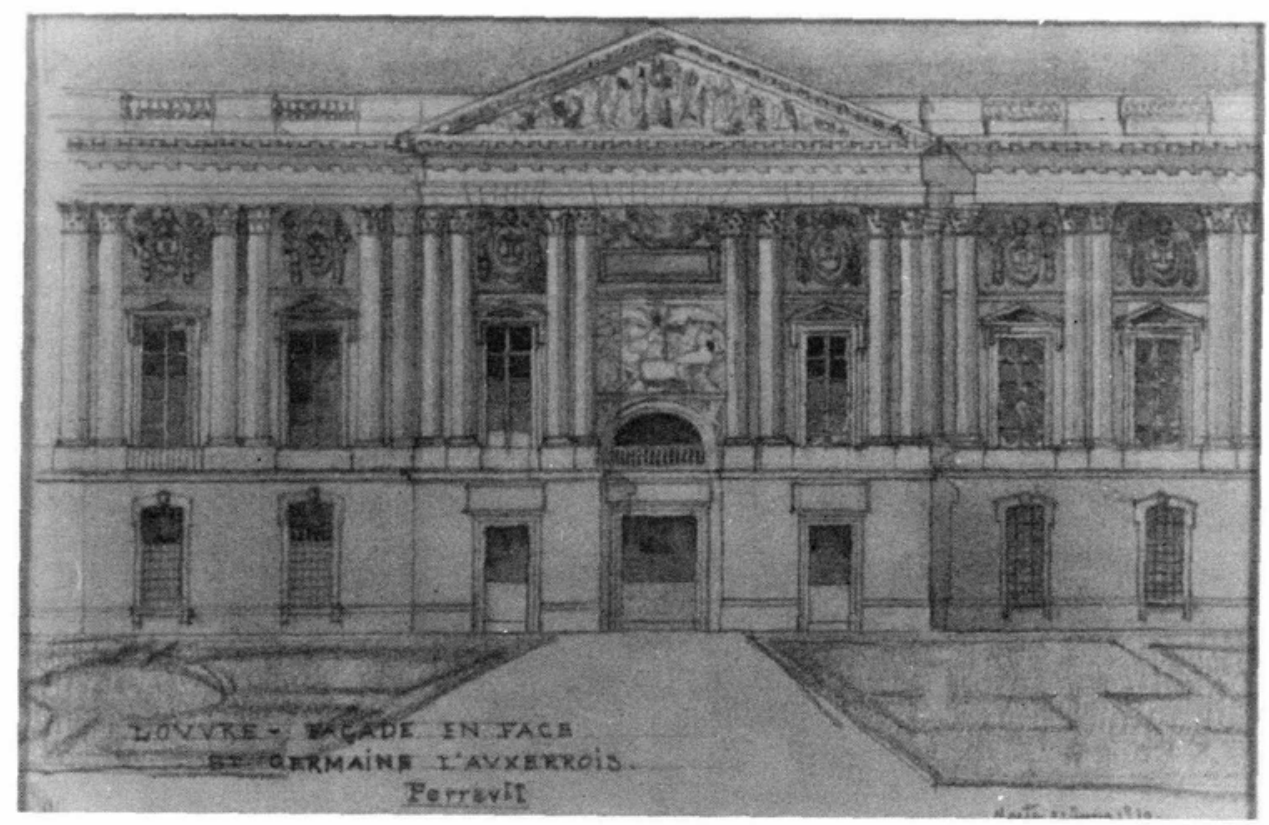

5. El Louvre, fachada frente a Saint Germain L'Auxerrois, de Claude Perrault. Dibujo iluminado a lápiz, libreta de apuntes, 1910. 
DOI: http://dx.doi.org/10.22201/iie.18703062e.1993.64.1667

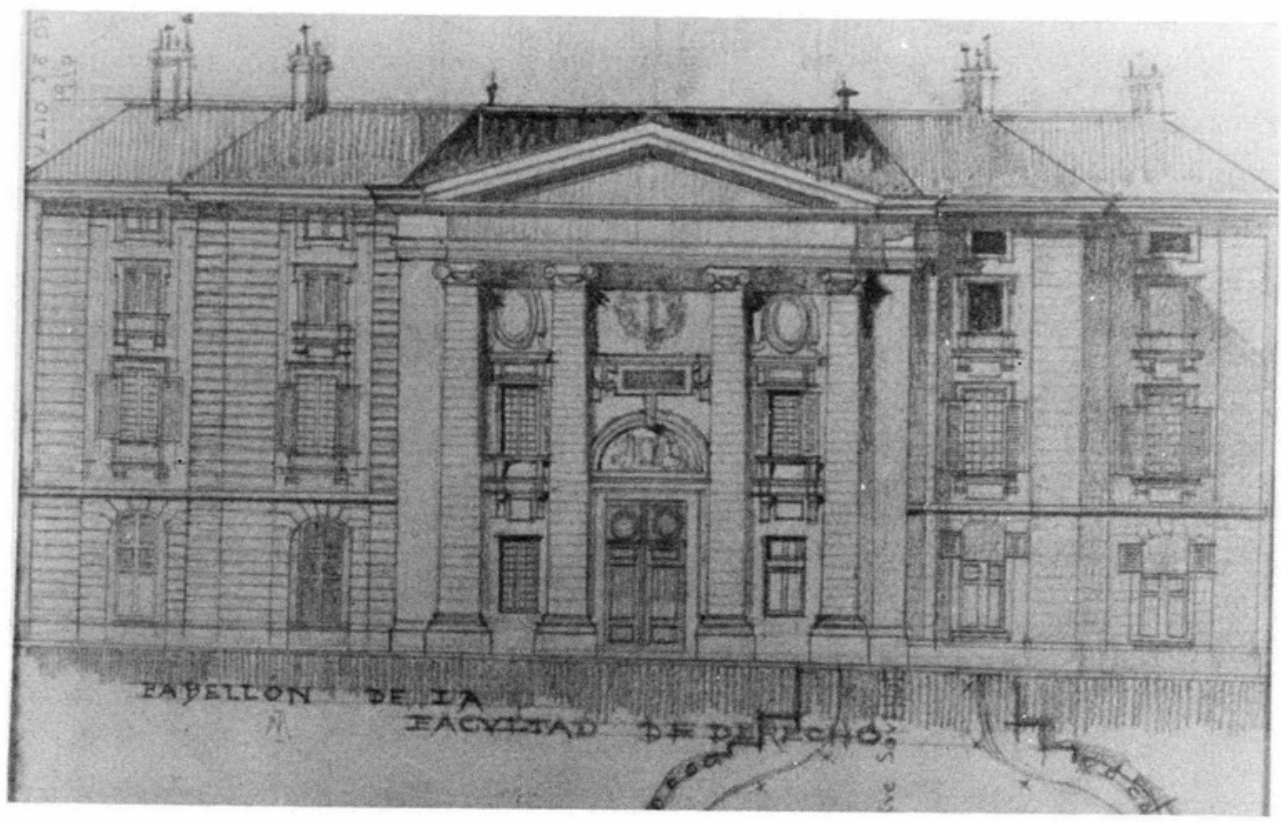

6. Pabellón de la Facultad de Derecho. Dibujo a lápiz, libreta de apuntes, 1910. 
DOI: http://dx.doi.org/10.22201/iie.18703062e.1993.64.1667

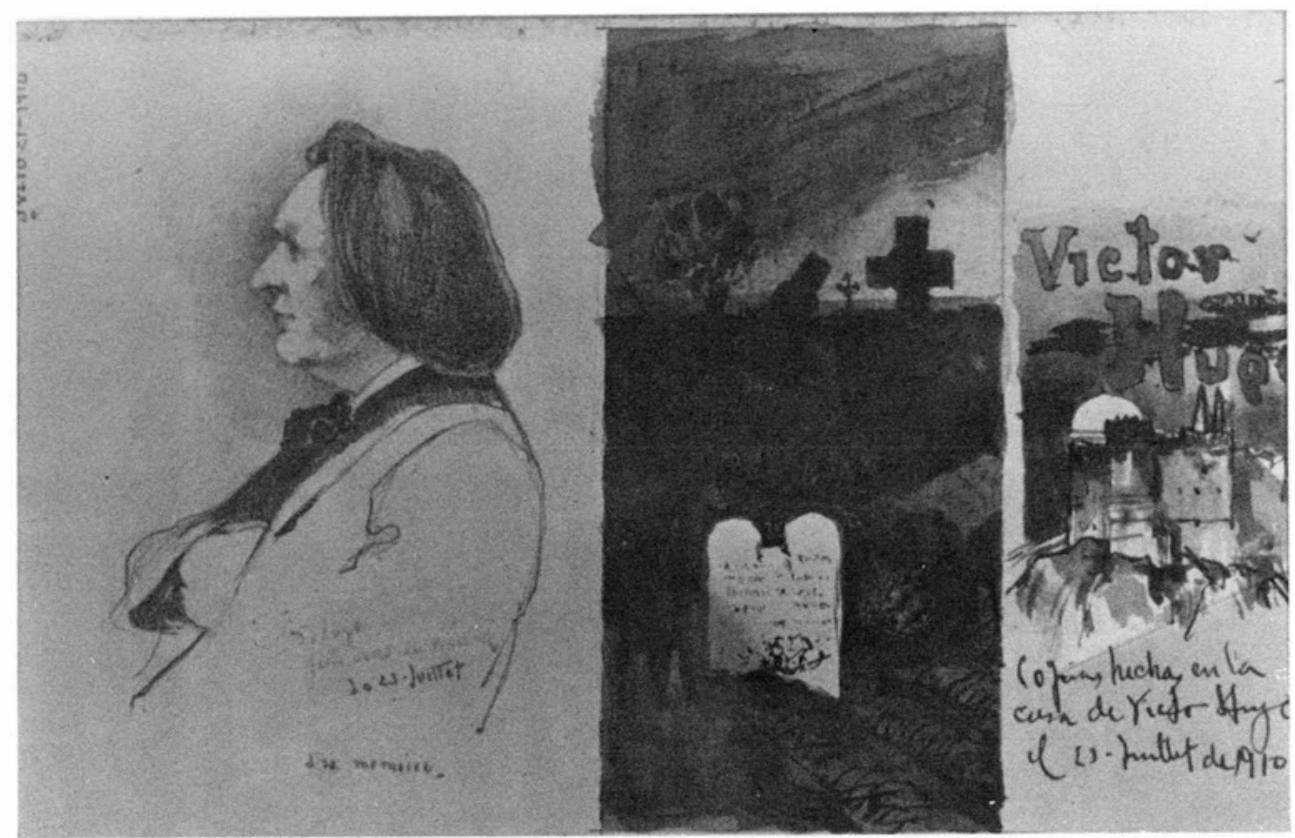

7. Copias hechas en la casa de Víctor Hugo. Dibujo a lápiz y tinta, libreta de apuntes. 
DOI: http://dx.doi.org/10.22201/iie.18703062e.1993.64.1667

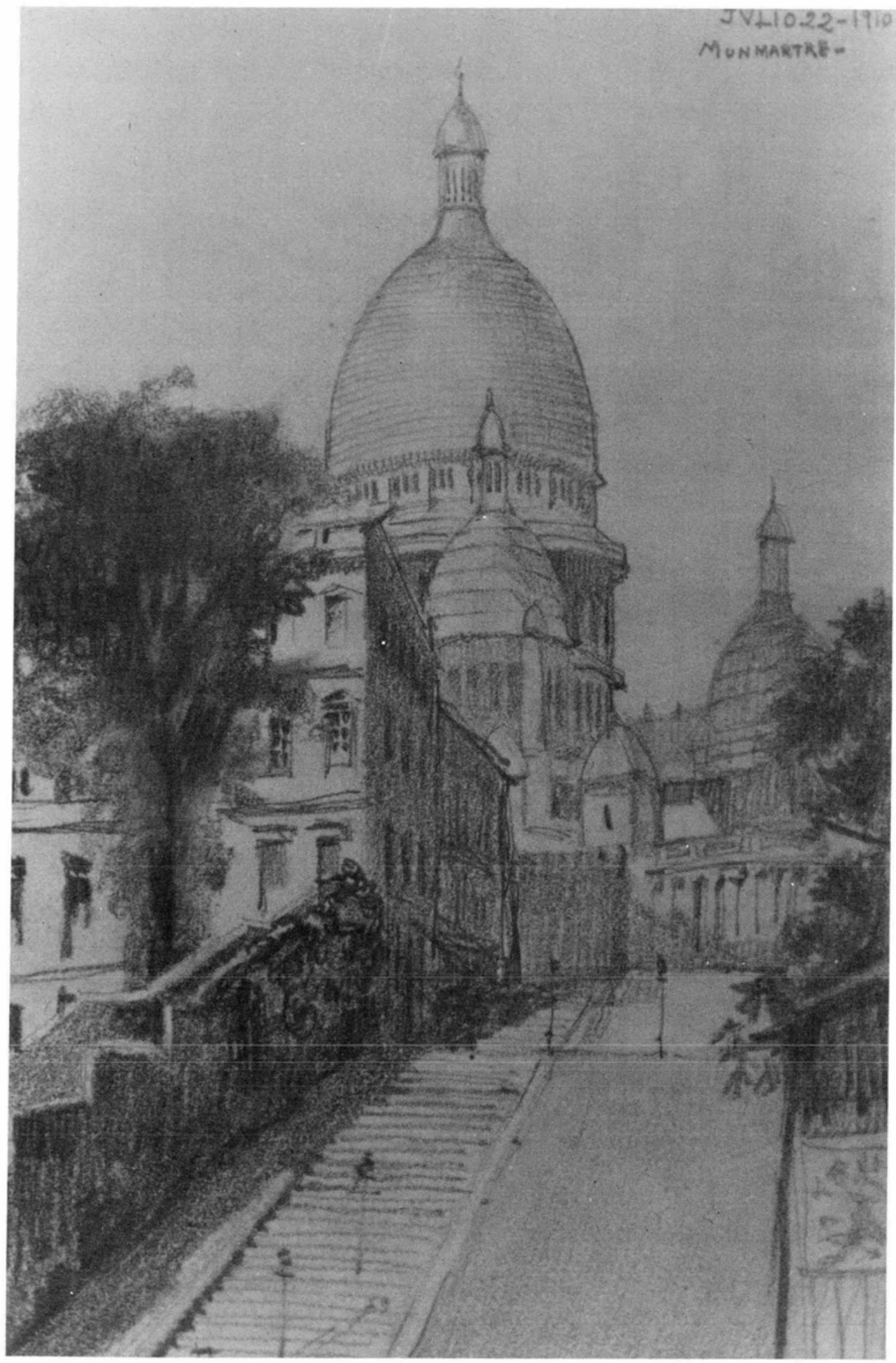

8. Montmartre. Dibujo a lápiz, libreta de apuntes. 
DOI: http://dx.doi.org/10.22201/iie.18703062e.1993.64.1667

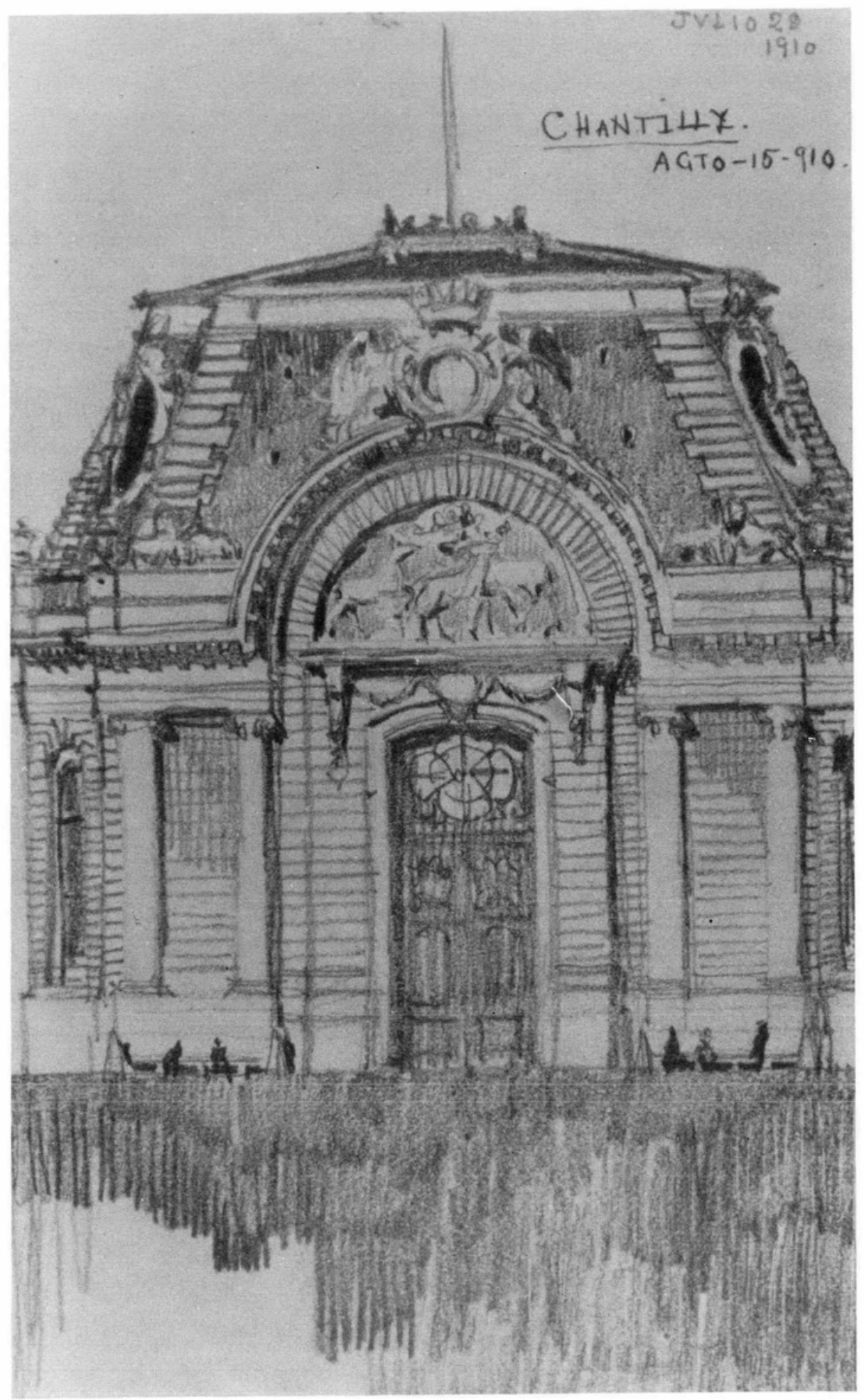

9. Chantilly. Dibujo a lápiz, libreta de apuntes. 
DOI: http://dx.doi.org/10.22201/iie.18703062e.1993.64.1667

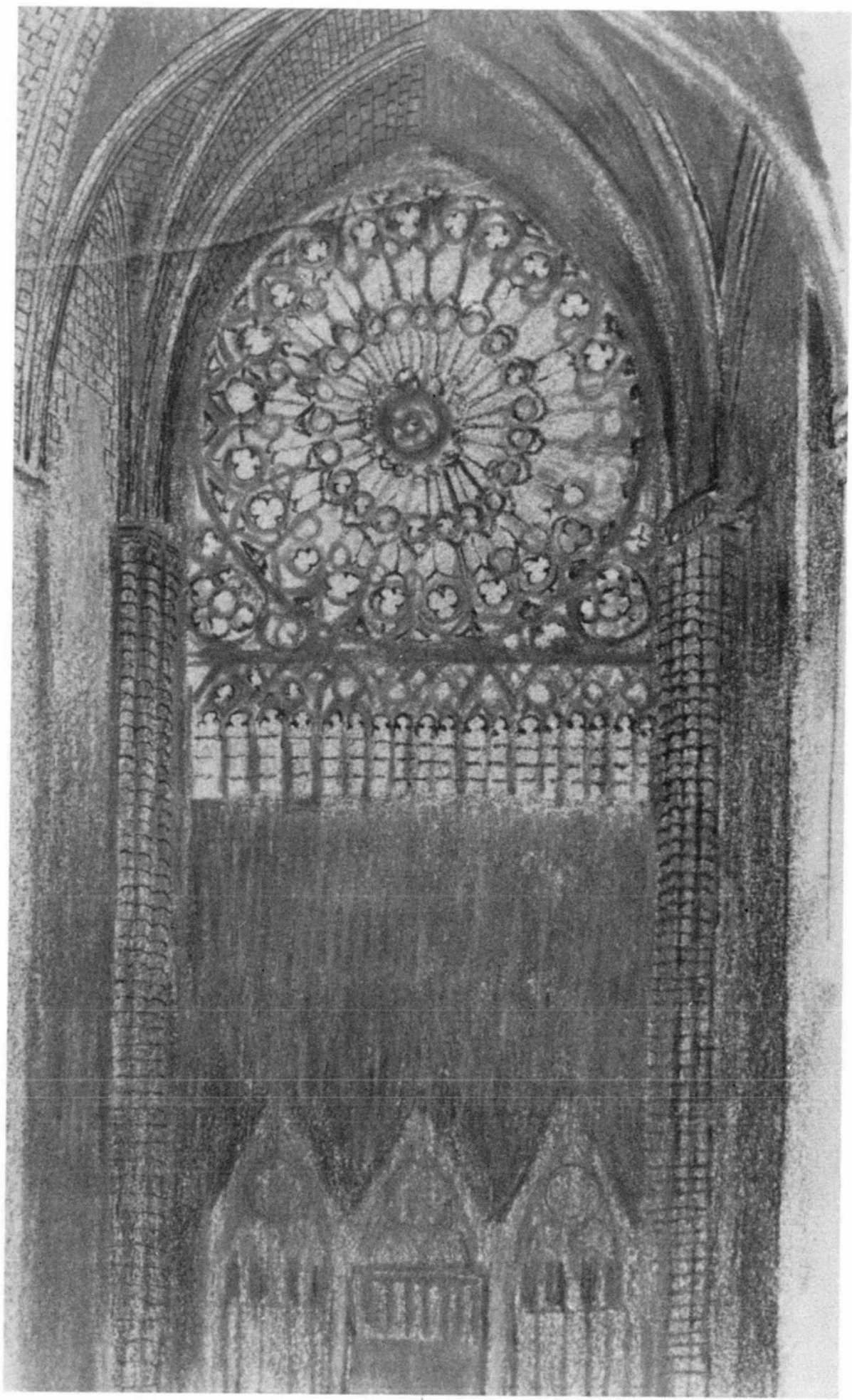

10. Interior de Notre Dame. Dibujo a lápices de colores, libreta de apuntes. 
DOI: http://dx.doi.org/10.22201/iie.18703062e.1993.64.1667

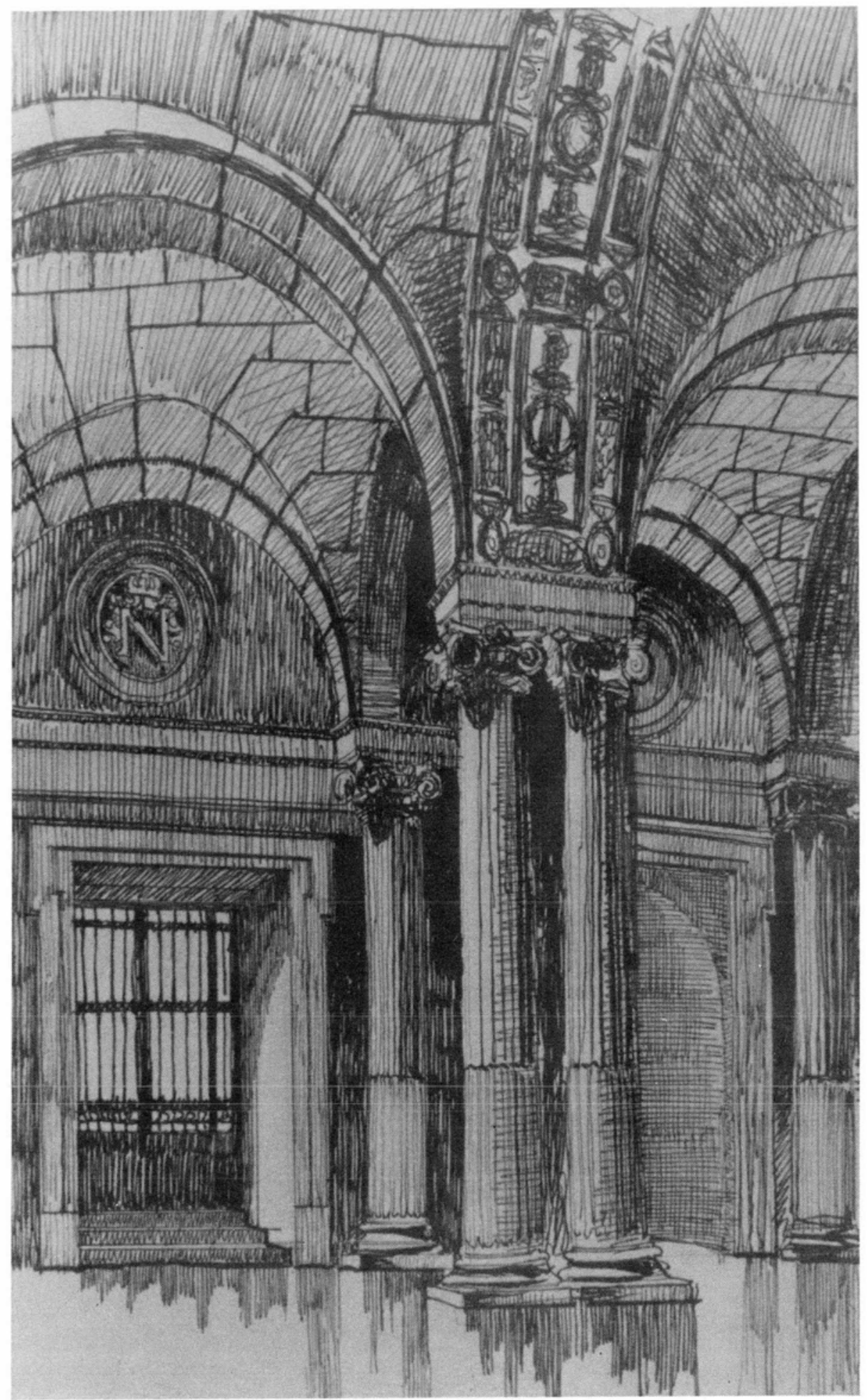

11. Interior del Louvre. Dibujo a tinta, libreta de apuntes. 
DOI: http://dx.doi.org/10.22201/iie.18703062e.1993.64.1667

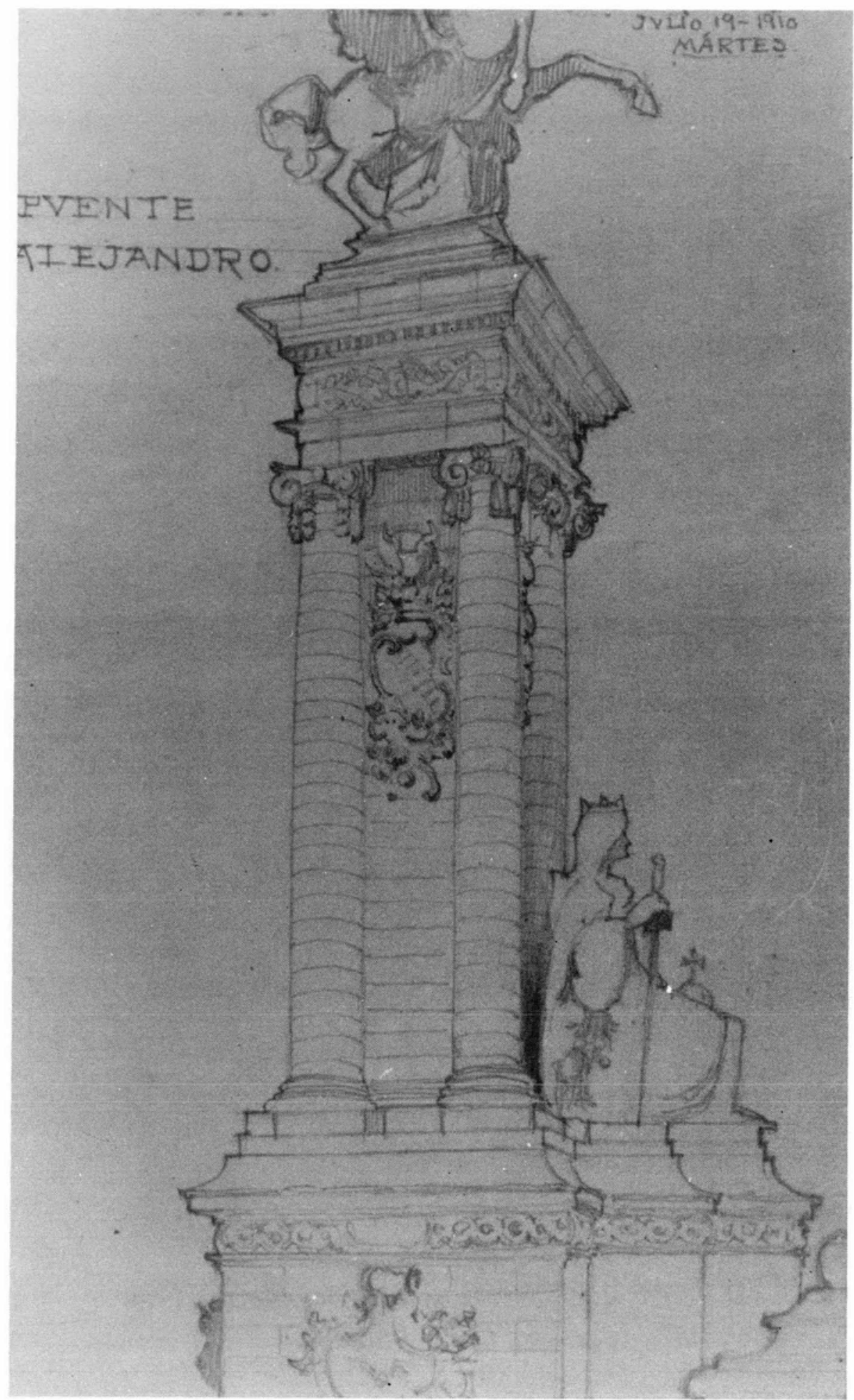

12. Puente de Alejandro II. Dibujo a lápiz, libreta de apuntes. 
DOI: http://dx.doi.org/10.22201/iie.18703062e.1993.64.1667

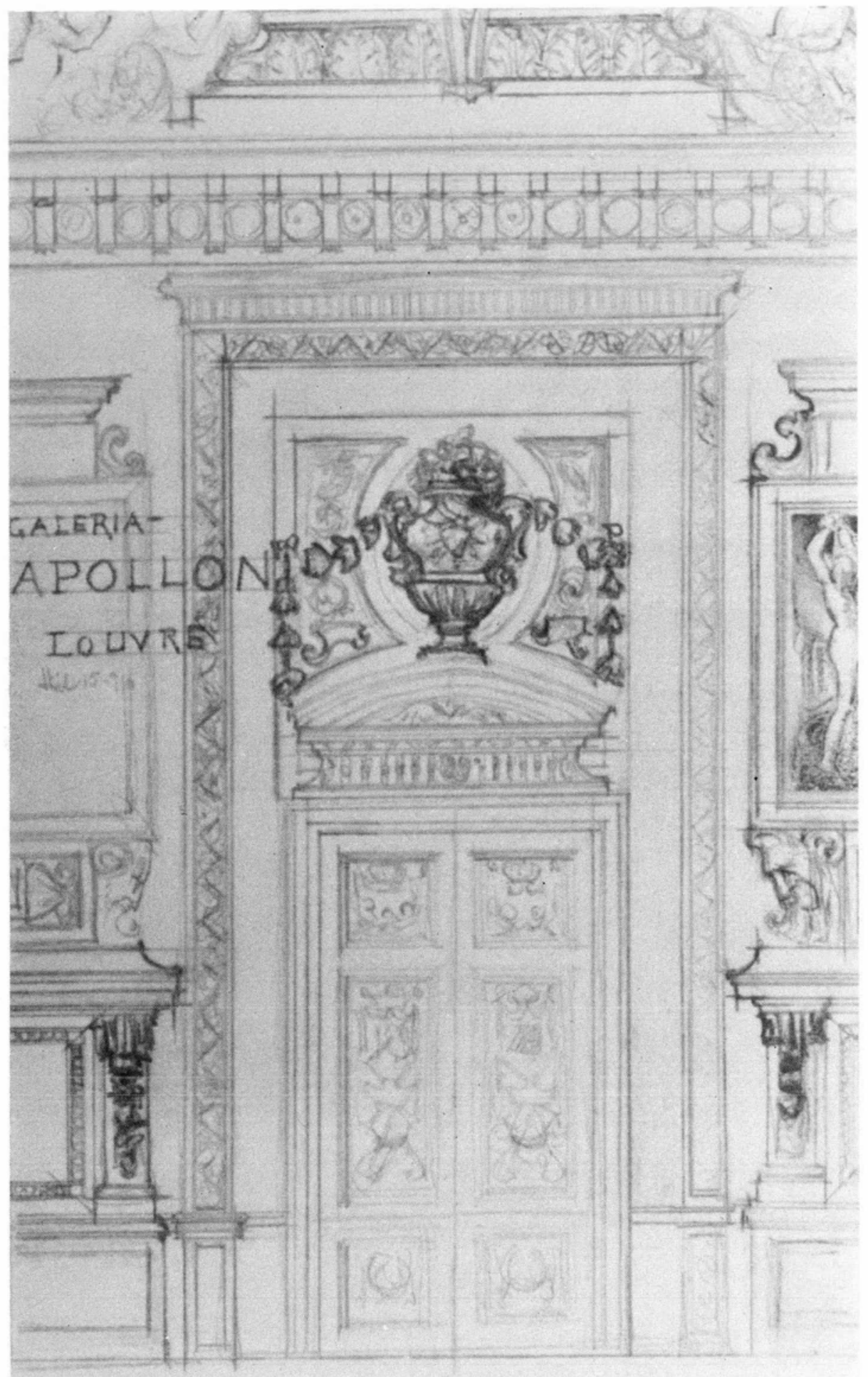

13. Detalle del interior de la Galería de Apolo, Louvre. Dibujo a lápiz, libreta de apuntes. 
DOI: http://dx.doi.org/10.22201/iie.18703062e.1993.64.1667

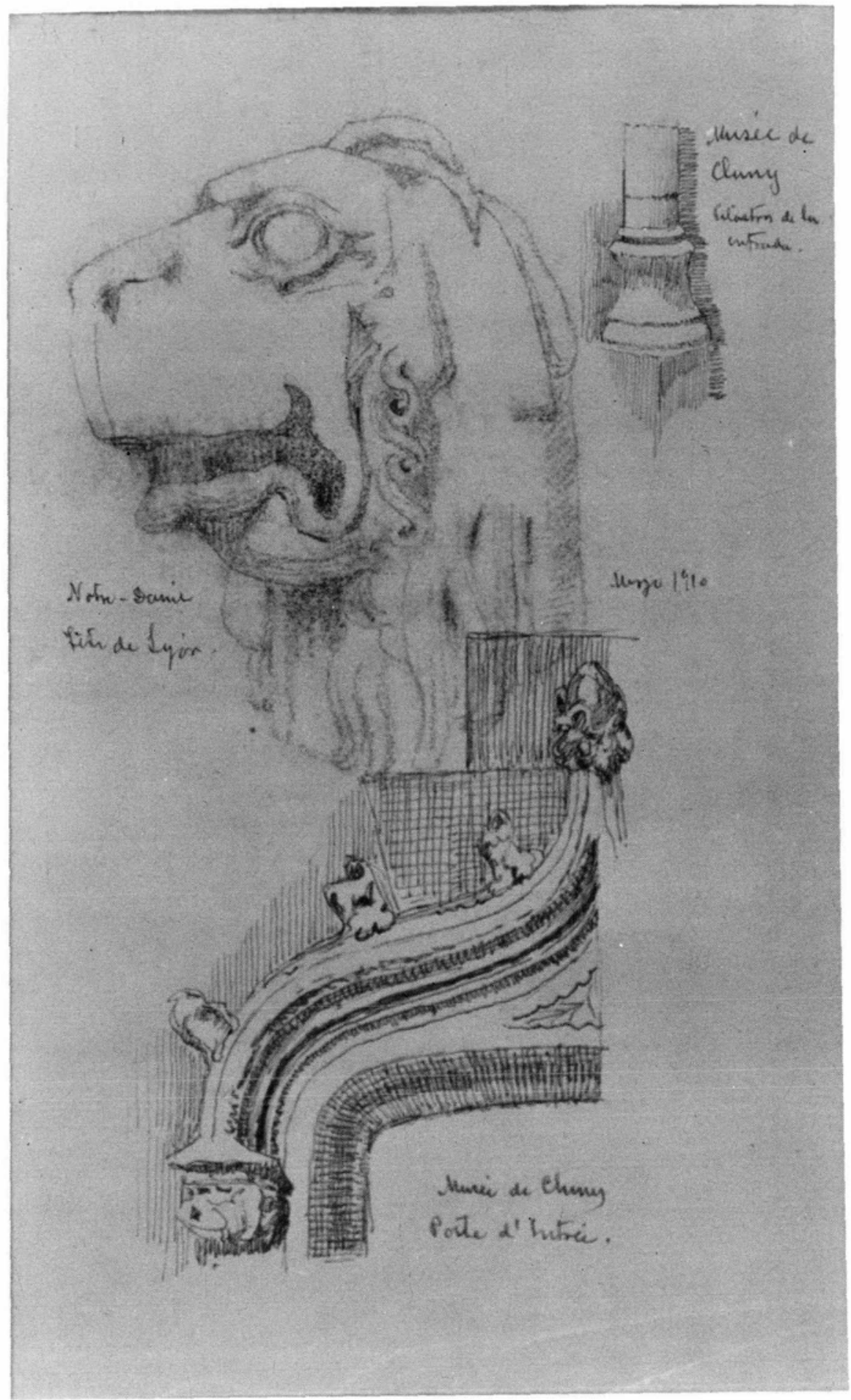

14. Candelabro en el Panteón. Dibujo a lápiz, libreta de apuntes. 
DOI: http://dx.doi.org/10.22201/iie.18703062e.1993.64.1667

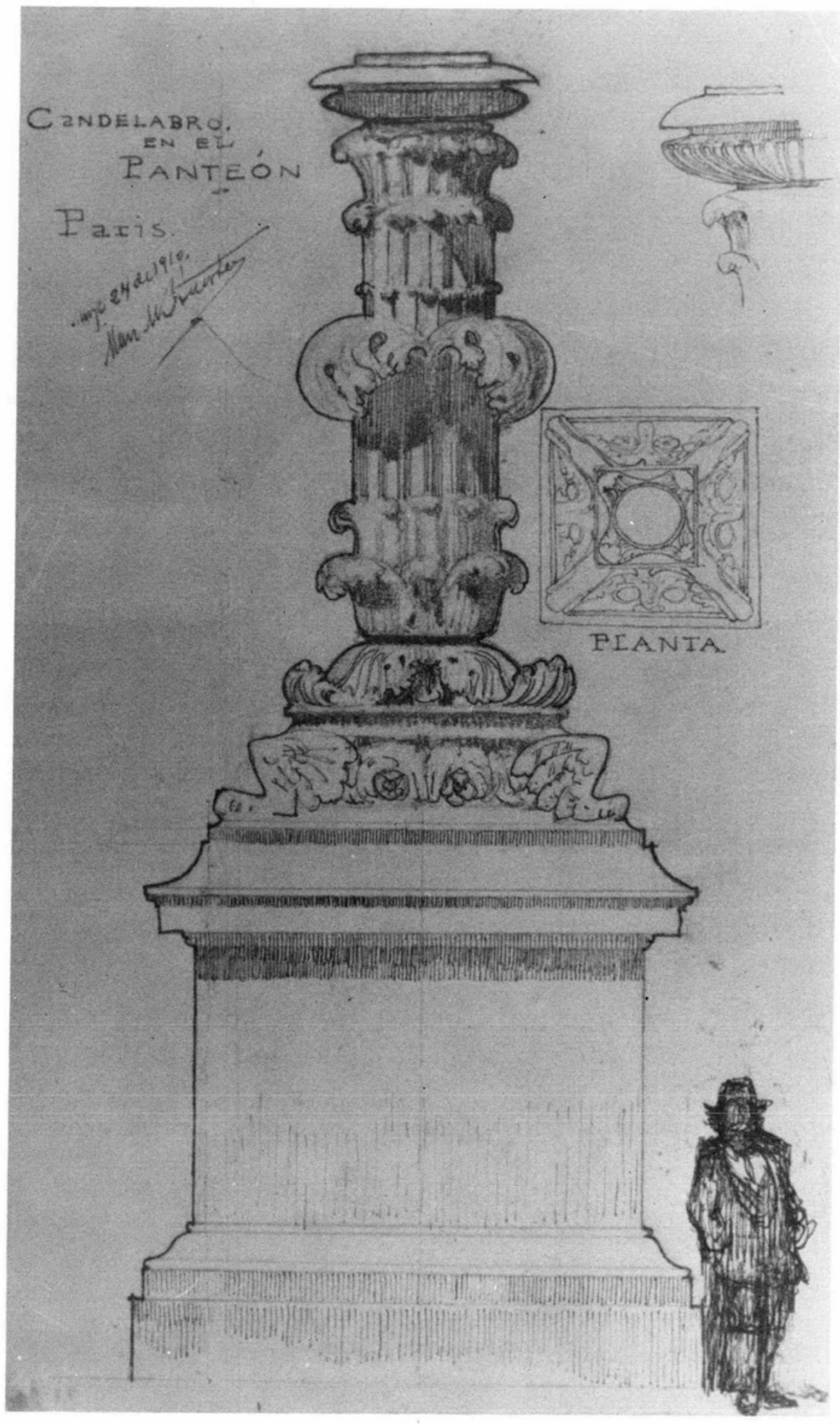

15. Apuntes de detalles del Museo Cluny y de Notre Dame. Dibujo a lápiz, libreta de apuntes. 
DOI: http://dx.doi.org/10.22201/iie.18703062e.1993.64.1667

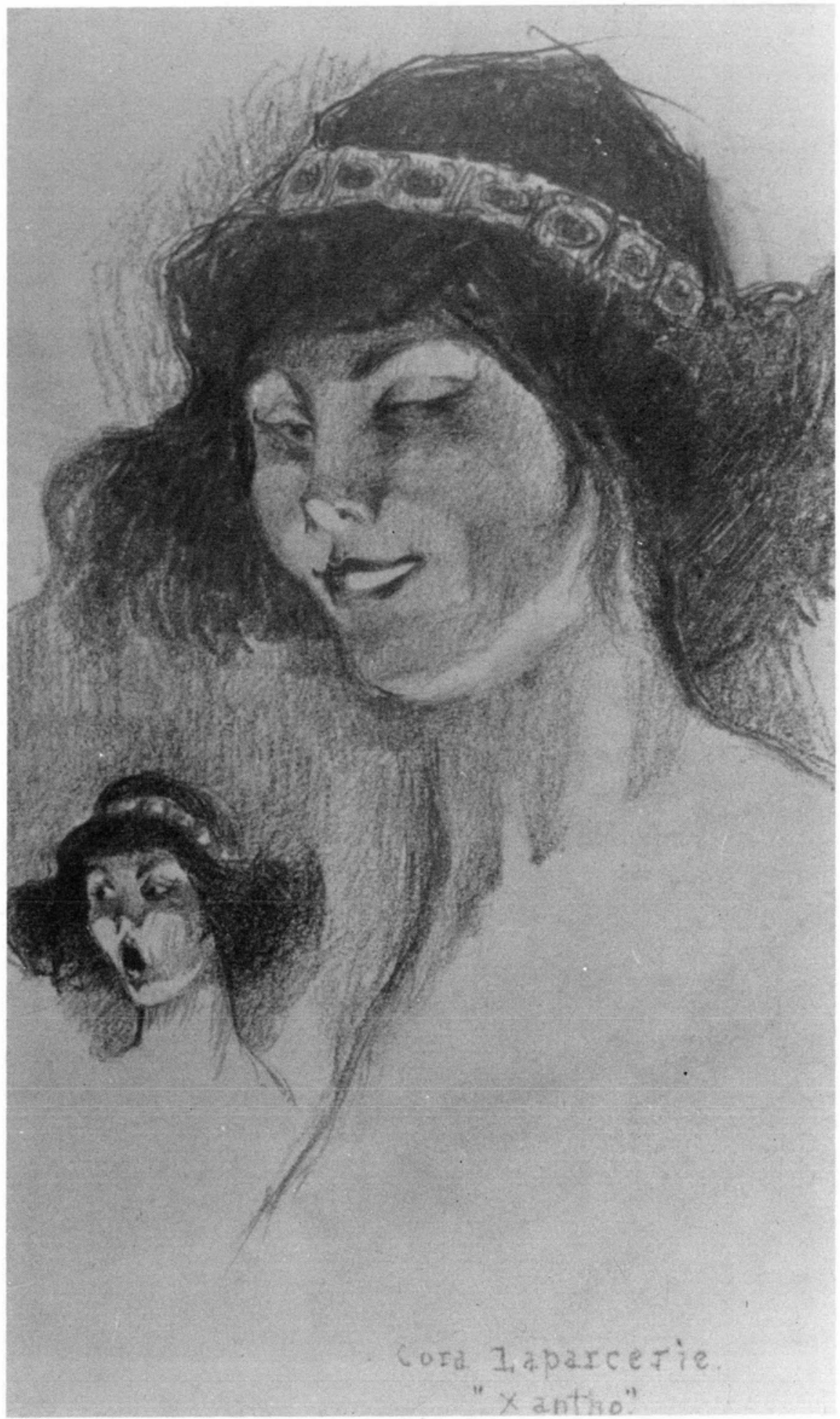

16. Cora Laparcerie en su papel de "Xantho". Dibujo a lápiz, libreta de apuntes. 